\title{
Antimalarial C-9 oxime derivatives from desmycosin, produced by click chemistry
}

\author{
Ayumi Tsutsui ${ }^{1}$, Tomoyasu Hirose ${ }^{1,2}$, Aki Ishiyama ${ }^{1}$, Masato Iwatsuki ${ }^{1}$, Arisa Yokota $^{2}$, Hitomi Maruyama ${ }^{2}$, \\ Hidehito Matsui ${ }^{1}$, Kazuhiko Otoguro ${ }^{1}$, Hideaki Hanaki ${ }^{1}$, Satoshi Ōmura ${ }^{1,2}$ and Toshiaki Sunazuka ${ }^{1,2}$
}

The Journal of Antibiotics (2013) 66, 191-194; doi:10.1038/ja.2012.113; published online 12 December 2012

Keywords: antimalarial; chloroquine-resistance; click chemistry; oxime derivative; triazole; tylosin

Plasmodium falciparum parasites remain the major cause of malaria, a serious and potentially fatal infectious disease worldwide, despite the intermittent introduction of several different successive classes of potent and effective drugs. According to the World Health Organization's Malaria Report (2011), an estimated 3.3 billion people were still at risk of malaria in 2010. ${ }^{1}$ Worldwide, in 2010, 99 countries and territories reported ongoing malaria transmission and a further 7 countries were trying to prevent the reintroduction of the disease, comprising a total of 106 countries in which malaria was considered endemic. ${ }^{1}$

The prevention and successful treatment of malaria is heavily dependent on antimalarial drugs. Chloroquine proved to be a remarkable safer, cheap and extremely effective antimalarial drug, serving as the frontline antimalarial treatment from its introduction in the mid-1940s to the 1990 s. $^{2}$ However, the malaria parasite has continually proved to be particularly efficient at developing resistance to virtually all drugs used to control it. Chloroquine-resistant parasites quickly emerged and spread worldwide, rendering the drug useless in many locations. The same scenario is being witnessed with the latest in the long line of potent antimalarials, artemisinin. Therefore, there is a continuing need for new antimalarial drugs that are effective, safe, affordable and easy to use and which, ideally, have a novel mode of action.

In our institute, we have focused on the screening and synthesis of antimalarial agents from microbial metabolites including antibacterial macrolides. ${ }^{3-5}$ In 2007, azithromycin, a 15 -membered antibacterial macrolide, was found to possess potent antimalarial activity by Fidock and co-workers. ${ }^{6}$ Azithromycin is a slow-acting antimalarial that targets the parasite apicoplast and its prokaryotic ribosomes. The effects of its action increase with prolonged incubation time (from one to two generations), giving an $\mathrm{IC}_{50}$ in the nano-molar range. Continuously, new derivatives of azithromycin have been developed with the aim to improve activity and selectivity for the malaria parasite. $^{7}$ Another macrolide antibiotic, tylosin, was first isolated by McGuire and co-workers ${ }^{8}$ in 1961 , and is a 16-membered macrolide isolated from a culture broth of Streptomyces fradiae. In 1984,
McColm and McHardy ${ }^{9}$ reported that tylosin demonstrated antimalarial activity against $P$. falciparum strain Liverpool $\left(\mathrm{IC}_{50}=0.1 \mu \mathrm{g} \mathrm{ml}^{-1}\right)$. However, there have been no subsequent reports concerning the antimalarial activity of tylosin or its derivatives. In this short note, we report that novel C-9 oximes of desmycosin express antimalarial activity against chloroquine-resistant P. falciparum $\mathrm{K} 1{ }^{10}$ malaria parasites.

The removal of mycarose from tylosin can be accomplished under mild acidic hydrolysis to give desmycosin, a known minor component in the fermentation broth of the tylosin-producing strain. ${ }^{11}$ The antimicrobial activity of desmycosin is potent but slightly lower than that of tylosin, but it has almost no efficacy in vivo when given orally. ${ }^{11}$ Likewise, C-9 oxime derivatives of tylosin and desmycosin have been evaluated in bioassays, but did not show better antimicrobial activity than tylosin. ${ }^{12}$ Our work on tylosin analog synthesis produced C-9 oximes of desmycosin (3, 6 and 7), prepared from dimethoxydesmycosin $(\mathbf{1})^{13}$ by oxime formation with corresponding hydroxylamines $\mathrm{HCl}^{14}$ and acid hydrolysis of dimethoxyacetal moiety in good yields, respectively. These analogs showed antimicrobial activities, similar to or slightly lower than that of desmycosin, (Scheme 1, Table 1). We specifically tested for antimalarial activity in all new analogs derived from tylosin. Moreover, as the discovery of the antimicrobial alkyne-bearing lead compounds (6 and 7) for antimicrobial activities, our efforts have focused on the preparation of new analogs in this series utilizing 'click chemistry', which provides an important approach for simple and rapid evaluation of functional activity. The concept of 'click chemistry' was originally introduced by Kolb, Finn and Sharpless in 2001. ${ }^{15}$ It incorporates powerful and selective reactions for efficient synthesis of interesting compounds and combinatorial libraries through heteroatom links. The advantages of 'click chemistry' in biological studies of macrolides have recently been clearly demonstrated in our laboratory. ${ }^{16,17}$

The alkyne-bearing oximes (6 and 7) are intermediates allowing generation of targeted triazole compounds. Anti-selective triazole formation was carried out with a catalytic amount of $\mathrm{Cu}(\mathrm{MeCN})_{4} \mathrm{PF}_{6}$

${ }^{1}$ Kitasato Institute for Life Sciences, Kitasato University, Tokyo, Japan and ${ }^{2}$ Graduate School of Infection Control Sciences, Kitasato University, Tokyo, Japan Correspondence: Professor S Ōmura or Professor T Sunazuka, Kitasato Institute for Life Sciences, Kitasato University, 5-9-1 Shirokane, Minato-ku, Tokyo 108-8641, Japan. E-mail: omuras@insti.kitasato-u.ac.jp or sunazuka@lisci.kitasato-u.ac.jp

Received 20 September 2012; revised 18 October 2012; accepted 26 October 2012; published online 12 December 2012 

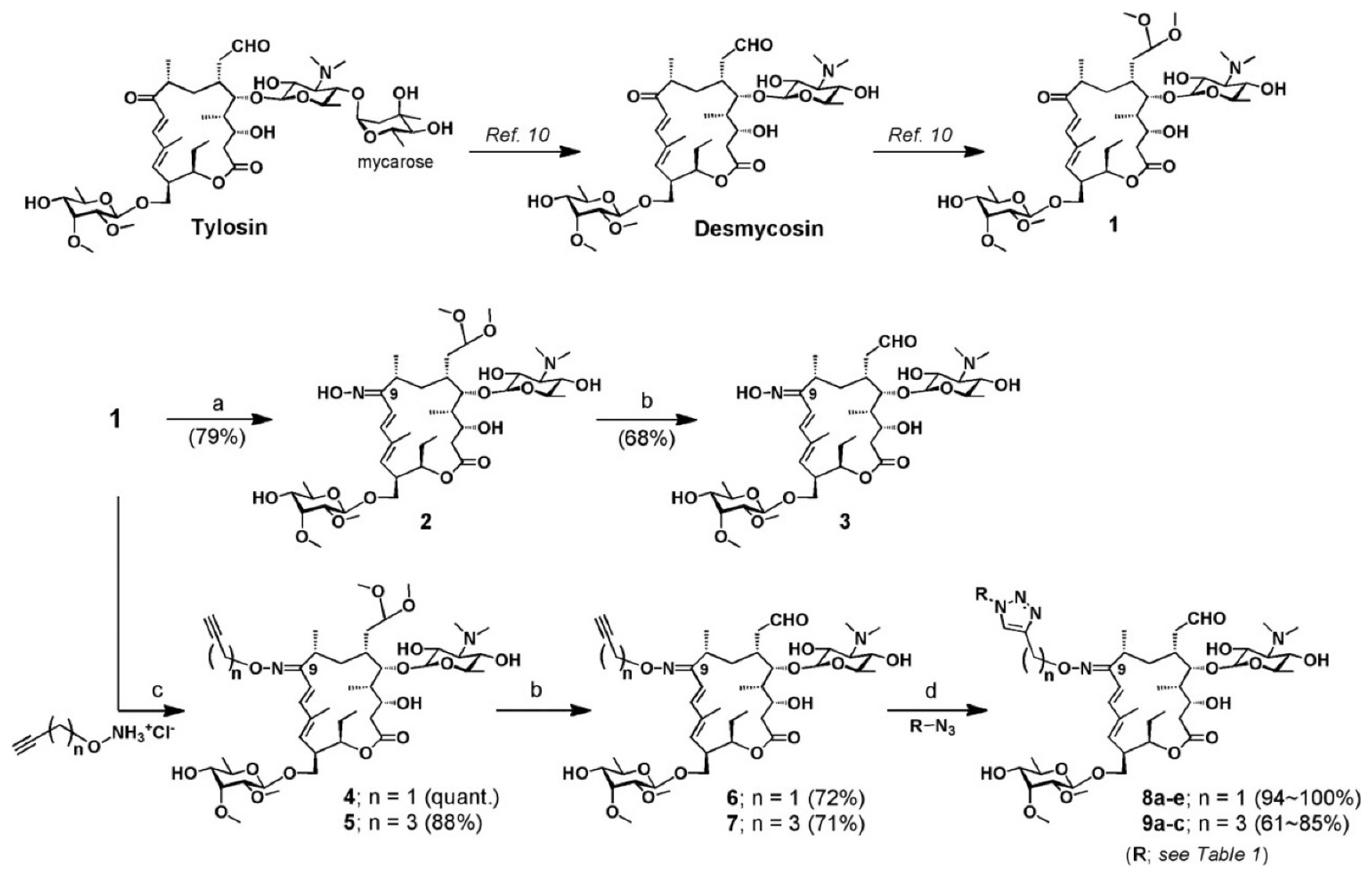

Scheme 1 Preparation of $\mathrm{C}-9$ oxime derivatives via desmycosin from tyrosin: a) $\mathrm{NH}_{2} \mathrm{OH} \bullet \mathrm{HCl}$, pyrdine; b) $\mathrm{TsOH}, \mathrm{PPTS}, \mathrm{CH} \mathrm{CN}_{3}$; c) $\mathrm{MeOH}$, pyridine; d) Azide reagents, $\mathrm{Cu}(\mathrm{MeCN})_{4} \mathrm{PF}_{6}, \mathrm{TBTA}, \mathrm{Cu}(0)$ turning, $\mathrm{MeOH}$. Ts, p-toluenesulfonyl; PPTS, pyridinium p-toluenesulfonate; TBTA, tris(benzyltriazolylmethyl)amine.

and tris-(benzyltriazolylmethyl)amine (TBTA) ${ }^{18}$ in $\mathrm{MeOH}$ at room temperature to afford the corresponding triazoles $(\mathbf{8} \mathbf{a}-\mathbf{e}$ and $\mathbf{9 a}-\mathbf{c})$ in good yields, respectively (61-100\%, see Supplementary Information; for example, compound 9a was 61\% yield) (Representative example (Compound 9a); To a solution of compound 7 (5.2 mg, $6.1 \mu \mathrm{mol}$ ) in $\mathrm{MeOH}$ was added 3 -azidequinoline $(2.2 \mathrm{mg}, 12.9 \mu \mathrm{mol})$, TBTA $(0.04 \mathrm{mg}, 0.75 \mu \mathrm{mol}), \mathrm{Cu}\left[\mathrm{Me}(\mathrm{CN})_{4}\right] \mathrm{PF}_{6}(0.01 \mathrm{mg}, 0.027 \mu \mathrm{mol})$ and a small piece of $\mathrm{Cu}(0)$ turning in $\mathrm{MeOH}(0.5 \mathrm{ml})$ at room temperature, and the resulting mixture was stirred for $20 \mathrm{~h}$. After removing of $\mathrm{Cu}(0)$ turning, then the reaction mixture was concentrated and purified by preparative TLC (Chloroform: acetone: $\left.\mathrm{NH}_{4} \mathrm{OH}=2: 1: 0.1\right)$ to give $9 \mathrm{a}(3.8 \mathrm{mg}, 61 \%)$ as a single isomer (not determined the geometry of the oxime): mp. $116.0 \sim 117.2^{\circ} \mathrm{C}$, $[\alpha]_{\mathrm{D}}^{28}-44.4\left(c 0.30, \mathrm{CHCl}_{3}\right)$; IR (KBr) $v \mathrm{~cm}^{-1} 3437,2972,2933$, $1718,1458,1379,1217,1167,1082,1063,960,754 ;{ }^{1} \mathrm{H}-\mathrm{NMR}$ $\left(600 \mathrm{MHz}, \mathrm{DMSO}-\mathrm{d}_{6}\right) \delta 9.59$ (s, $\left.1 \mathrm{H}\right), 9.43(\mathrm{~d}, J=2.1 \mathrm{~Hz}, 1 \mathrm{H}), 8.87$ $(\mathrm{d}, J=2.1 \mathrm{~Hz}, 1 \mathrm{H}), 8.76(\mathrm{~s}, 1 \mathrm{H}), 8.12(\mathrm{~d}, J=8.0 \mathrm{~Hz}, 1 \mathrm{H}), 8.10$ (d, $J=8.0 \mathrm{~Hz}, 1 \mathrm{H}$ ), 7.84 (apparently t, $J=8.0 \mathrm{~Hz}, 1 \mathrm{H}$ ), 7.72 (apparently t, $J=8.0 \mathrm{~Hz}, 1 \mathrm{H}$ ), 7.42 (broad d, $J=15.5 \mathrm{~Hz}, 1 \mathrm{H}$ ), 5.73 (broad d, $J=15.5 \mathrm{~Hz}, 1 \mathrm{H}), 5.52(\mathrm{~d}, J=10.7 \mathrm{~Hz}, 1 \mathrm{H}), 4.84(\mathrm{~m}, 1 \mathrm{H}), 4.79$ $(\mathrm{d}, J=7.2 \mathrm{~Hz}, 1 \mathrm{H}), 4.48-4.40$ (complex $\mathrm{m}, 3 \mathrm{H}), 4.31(\mathrm{~d}, J=4.3 \mathrm{~Hz}$, $1 \mathrm{H}), 4.12-4.05$ (complex m, 3H), 3.72 (dd, $J=9.8,3.0 \mathrm{~Hz}, 1 \mathrm{H}), 3.70$ (m, $1 \mathrm{H}), 3.55-3.40$ (complex m, 4H), $3.37(\mathrm{~s}, 3 \mathrm{H}), 3.27(\mathrm{~s}, 3 \mathrm{H}), 3.13$ $(\mathrm{m}, 1 \mathrm{H}), 3.06(\mathrm{~m}, 1 \mathrm{H}), 2.99(\mathrm{~m}, 1 \mathrm{H}), 2.94(\mathrm{~m}, 1 \mathrm{H}), 2.90(\mathrm{dd}, J=8.2$, $2.8 \mathrm{~Hz} 1 \mathrm{H}), 2.86-2.71$ (complex m, $4 \mathrm{H}), 2.77(\mathrm{t}, J=7.3 \mathrm{~Hz}, 1 \mathrm{H}), 2.40-$ 2.17 (complex m, 3H), 2.38 (s, 6H), 2.07-1.93 (complex m, 4H), 1.78 $(\mathrm{m}, 1 \mathrm{H}), 1.71(\mathrm{~s}, 3 \mathrm{H}), 1.60-1.47$ (complex m, 3H), $1.23(\mathrm{~m}, 1 \mathrm{H}), 1.09$ $(\mathrm{d}, J=6.9 \mathrm{~Hz}, 3 \mathrm{H}), 1.02(\mathrm{~d}, J=6.1 \mathrm{~Hz}, 6 \mathrm{H}), 0.90(\mathrm{~d}, J=6.5 \mathrm{~Hz}, 3 \mathrm{H})$, $0.82(\mathrm{t}, J=7.4 \mathrm{~Hz}, 3 \mathrm{H}) ;{ }^{13} \mathrm{C}-\mathrm{NMR}\left(125 \mathrm{MHz}, \mathrm{DMSO}-\mathrm{d}_{6}\right) \delta 204.1$, 172.6, 147.9, 146.8, 143.1 (2C), 137.2, 135.2, 130.3 (2C), 128.9, 128.5, 128.1 (2C), 127.1, 125.4, 120.8, 112.8, 103.7, 100.7, 80.6, 80.1, 74.4, 72.7 (2C), 72.6 (2C), 70.6, 70.4, 69.7, 69.2 (2C), 68.8, 61.0, 58.1, 44.0, 43.1, 41.6 (3C), 35.2, 31.9, 28.5, 24.5, 21.7, 21.6, 19.3, 17.7 (2C), 17.7, 12.1, 9.7, 8.6; ESI-MS: calcd. for $\mathrm{C}_{53} \mathrm{H}_{79} \mathrm{~N}_{6} \mathrm{O}_{14}: 1023.5654[\mathrm{M}+\mathrm{H}]^{+}$, found $m / z: 1023.5643$.). The efficiency of the present 'click chemistry' process allowed the preparation of each triazole candidates with sufficient purity for in vitro antibacterial and antimalarial testing as shown in Table 1.

In in vitro tests using Staphylococcus aureus and Enterococcus faecalis, $O$-(3-quinolyltriazolylmethyl)oxime (8a) and O-phenylthiomethyltriazolyloxime $(\mathbf{8 c})$ were effective against both strains with MICs of $0.5-1 \mu \mathrm{g} \mathrm{ml}^{-1}$, similar to results obtained with the alkynebearing oximes (6 and 7). No superior analogs were found from this triazole series with respect to antibacterial properties. However, we obtained results for antimalarial activity in vitro that were different from what we expected. Although all C-9 oxime analogs (3, 6 and 7) showed no activity against the P. falciparum K1 strain, the newly synthesized triazoles demonstrated effective antimalarial properties. Our analysis indicated that the 3-quinolyltriazole function on the desmycosin framework is a promising structure responsible for expression of antimalarial activity in vitro $\left(\mathrm{IC}_{50}=0.7-2.0 \mu \mathrm{g} \mathrm{ml}^{-1}\right)$. The cytotoxicity of triazole analogs were measured by colorimetric 3-(4,5-dimethyl-2-thiazolyl)-2,5-diphenyl-2H-tetrazolium bromide (MTT) assay with human MRC-5 cells. ${ }^{10}$ All new analogs 
Table 1 In vitro antibacterial and antimalarial activities of tylosin, desmycosin and its derivatives

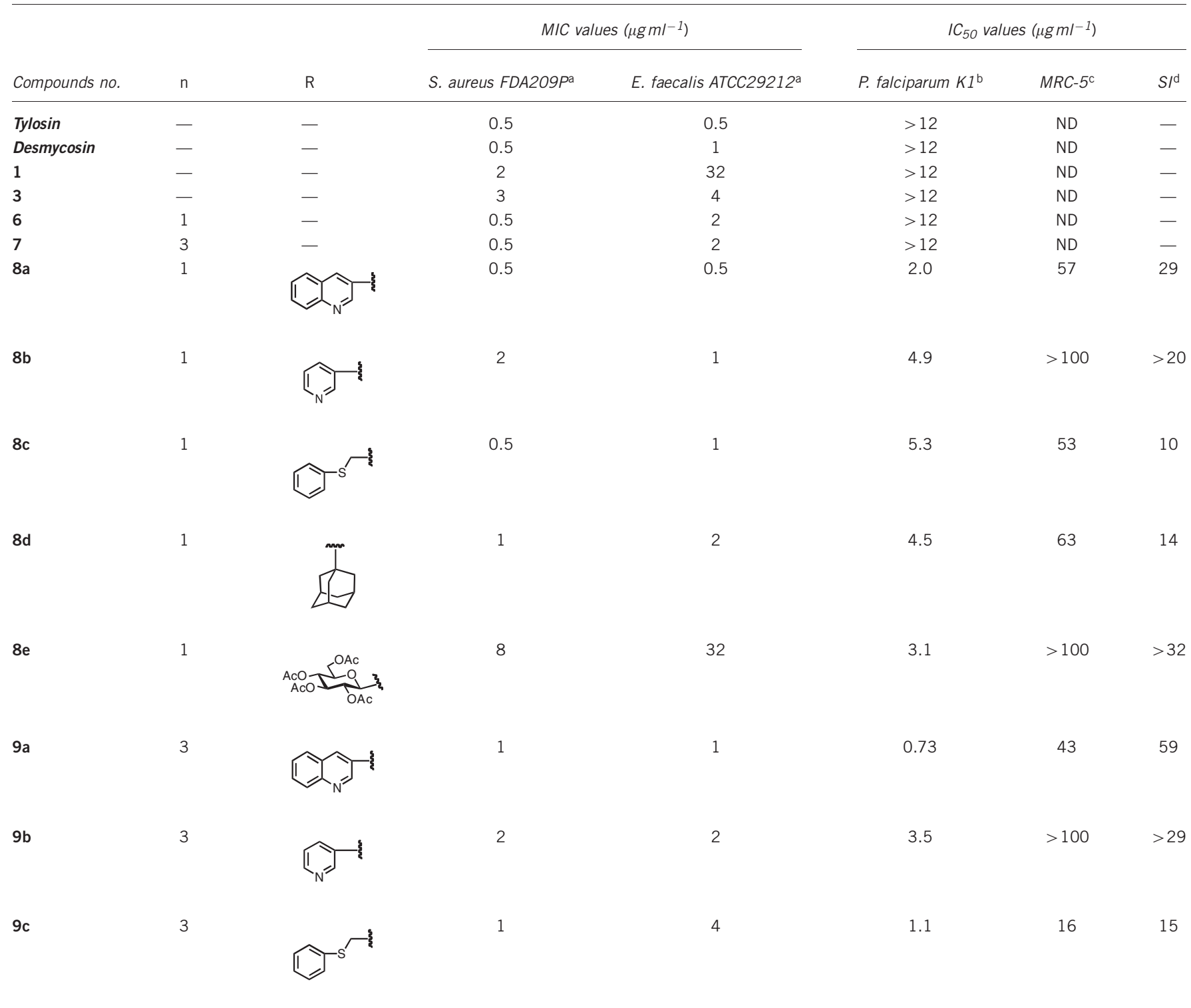

S. aureus FDA209P and E. faecalis ATCC29212: susceptible strains.

b. falciparum: chloroquine-resistant strain.

'Against human diploid ambryonic cell line (MRC-5 cells).

dSI (selectivity index): cytotoxicity (IC $C_{50}$ for the MRC-5 cell)/antimalarial activity (IC ${ }_{50}$ for the K1 strain).

(8a-e, 9a and 9b) showed comparatively low cytotoxicity with $\mathrm{IC}_{50}$ value of $43->100 \mu \mathrm{g} \mathrm{ml}^{-1}$, except for thioether (9c), and Selectivity Indexes (cytotoxicity [ $\mathrm{IC}_{50}$ for the MRC-5 cell]/ antimalarial activity $\left[\mathrm{IC}_{50}\right.$ for the $\mathrm{K} 1$ strain]) of these analogs were promising. Furthermore, the in vivo antimalarial activity of $\mathbf{9 a}$ and $\mathbf{9 c}$ per s.c. (conducted by using a rodent malaria-derived $P$. berghei strain according to the 4-days suppressive test established by Peters and co-workers) ${ }^{10,19,20}$ was evaluated. Test compounds (9a and 9c) were solubilized in $10 \%$ DMSO-0.5\%Tween 80 aqueous solution, each $30 \mathrm{mg} \mathrm{kg}^{-1}$ of which were administered s.c. to mice $2 \mathrm{~h}$ after the infection (Day 0 ) and once a day for three consecutive days (Days 1-3). One day after the last treatment (Day 4), thin blood films were made from the tail blood of mice, and the parasitaemia was determined. The results showed $67 \%$ and $51 \%$ inhibition of parasite growth, respectively (data not shown).
In conclusion, we have described a highly efficient approach to the synthesis of modular type analogs at C-9 of desmycosin through the use of 'click chemistry'. The triazole-possessing analogs of desmycosin turned out to be potent antimalarial agents. Based on these findings, further structural optimization and structure-activity relationship studies of this class of compounds are currently in progress.

\section{ACKNOWLEDGEMENTS}

This work was supported by a grant of the 21st Century COE Programme, together with funds from the Quality Assurance Framework of Higher Education from the Ministry of Education Culture, Sports, Science and Technology (MEXT), Japan. We are grateful to Dr Kenichiro Nagai and Ms Noriko Sato (Kitasato University) for measurements of mass and NMR spectra, and Ms Miyuki Namatame (Kitasato University) for her technical assistance. 
1 World Health Organization. World Malaria Report 2011. Available at http:// www.who.int/malaria/world malaria report_2011/en/.

2 Meshnick, S. R. \& Dobson, M. J. in Antimalarial Chemotherapy: Mechanisms of Action Resistance and New Directions in Drug Discovery (ed. Rosenthal, P. J.) Part 1, 15-25 (Humana Press, Totowa, 2001).

3 Iwatsuki, M. et al. In vitro and in vivo antimalarial activity of puberulic acid and its new analogs, viticolins A-C, produced by Penicillium sp. FKI-4410. J. Antibiot. 64, 183-188 (2011).

4 Ishiyama, A. et al. Borrelidin, a potent antimalarial: stage-specific inhibition profile of Plasmodium falciparum. J. Antibiot. 64, 381-384 (2011).

5 Tsutsui, A. et al. Boromycin derivatives: synthesis and antimalarial activity in vitro and in vivo. Heterocycles 82, 289-295 (2010).

6 Sidhu, A. B. S. et al. In vitro efficacy, resistance selection, and structural modeling studies implicate the malarial parasite apicoplast as the target of azithromycin. J. Biol. Chem. 282, 2494-2504 (2007).

7 Starcevic, K. et al. Novel hybrid molecules based on 15-membered azalide as potential antimalarial agents. Eur. J. Med. Chem. 49, 365-378 (2012).

8 McGuire, J. M. et al. Tylosin, a new antibiotic. I. Microbiological studies. Antibiot. Chemother. 11, 320-327 (1961).

$9 \mathrm{McColm}, \mathrm{A}$. A. \& McHardy, N. Evaluation of a range of antimicrobial agents against the parasitic protozoa, Plasmodium falciparum, Babesia rodhaini and Theileria parva in vitro. Ann. Trop. Med. Parasitol. 78, 345-354 (1984).

10 Otoguro, K. et al. Potent antimalarial activities of the polyether antibiotic, X-206. J. Antibiot. 54, 658-663 (2001).
11 Hamill, R. L. et al. Tylosin, a new antibiotic. II. Isolation, properties and preparation of desmycosin, a microbiologically active degradation product. Antibiot. Chemother (Basel) 11, 328-334 (1961).

12 Ruggieri, C. et al. Synthesis and antibacterial activitiy of 9-0-[(2-methoxyethoxy)methyl]oximes of tylosin and demycarosyltylosin. J. Antibiot. 42, 1443-1445 (1989)

13 Tsuzuki, K., Matsubara, H., Nakagawa, A. \& Ōmura, S. Synthesis and antimicrobial activites of 9-O-acyl derivatives of tylosin and demycarosyltylosin. J. Antibiot. 39, 1784-1787 (1986)

14 Grochowski, E. \& Jurczak, J. A new synthesis of O-alkylhydroxyamines. Synthesis (Mass) 10, 682-684 (1976).

15 Kolb, H. C., Finn, M. G. \& Sharpless, K. B. Click chemistry: diverse chemical function from a few good reactions. Angew. Chem. Int. Ed. 40, 2004-2021 (2001).

16 Hirose, T. et al. Rapid 'SAR' via click chemistry: an alkyne-bearing spiramycin is fused with diverse azides to yield new triazole-antibacterial candidates. Heterocycles 69 , 55-61 (2006).

17 Sugawara, A. et al. Design and synthesis via click chemistry of 8,9-anhydroerythromycin A 6,9-hemiketal analogues with anti-MRSA and -VRE activity. Bioorg. Med. Chem. Lett. 17, 6340-6344 (2007).

18 Chan, T. R., Hilgraf, R., Sharpless, K. B. \& Fokin, V. V. Polytriazoles as copper(I)stabilizing ligands in catalysis. Org. Lett. 6, 2853-2855 (2004).

19 Otoguro, K. et al. In vitro and in vivo antimalarial activities of the monoglycoside polyether antibiotic, K-41 against drug resistant strains of Plasmodia. J. Antibiot. 55, 832-834 (2002).

20 Peters, W., Portus, J. H. \& Robinson, B. L. Chemotherapy of rodent malaria. XXII. Value of drug-resistant strains of Plasmodium berghei in screening for blood schizontocidal activity. Ann. Trop. Med. Parasitol. 69, 155-171 (1975).

Supplementary Information accompanies the paper on The Journal of Antibiotics website (http://www.nature.com/ja) 